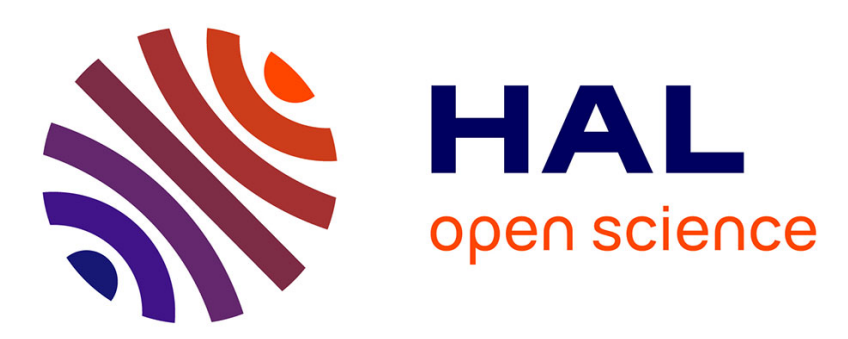

\title{
Post-fire selective thinning of Arbutus unedo L. coppices keeps animal diversity unchanged: the case of ants
}

\author{
Lídia Quevedo, Xavier Arnan, Olga Boet, Anselm Rodrigo
}

\section{To cite this version:}

Lídia Quevedo, Xavier Arnan, Olga Boet, Anselm Rodrigo. Post-fire selective thinning of Arbutus unedo L. coppices keeps animal diversity unchanged: the case of ants. Annals of Forest Science, 2014, 71 (8), pp.897-905. 10.1007/s13595-014-0381-5 . hal-01102900

\section{HAL Id: hal-01102900 \\ https://hal.science/hal-01102900}

Submitted on 13 Jan 2015

HAL is a multi-disciplinary open access archive for the deposit and dissemination of scientific research documents, whether they are published or not. The documents may come from teaching and research institutions in France or abroad, or from public or private research centers.
L'archive ouverte pluridisciplinaire HAL, est destinée au dépôt et à la diffusion de documents scientifiques de niveau recherche, publiés ou non, émanant des établissements d'enseignement et de recherche français ou étrangers, des laboratoires publics ou privés. 


\title{
Post-fire selective thinning of Arbutus unedo L. coppices keeps animal diversity unchanged: the case of ants
}

\author{
Lídia Quevedo • Xavier Arnan • Olga Boet • \\ Anselm Rodrigo
}

Received: 23 February 2014 / Accepted: 14 April 2014 / Published online: 5 June 2014

(C) INRA and Springer-Verlag France 2014

\begin{abstract}
- Context In the Mediterranean area, different post-fire management strategies are used for coppices of resprouting species to promote a more regular forest structure, enhance plant growth, and reduce fire risk. However, the effects of these management treatments on forest-associated fauna are unknown, which in turn could be limiting their beneficial effects.

- Aims The aim of this work was to determine whether forest management of a recently burned area dominated by a vigorous resprouting tree species (Arbutus unedo L.) affects ant communities.

- Methods Ant communities, sampled using pitfall traps, were examined from unmanaged and selective thinning coppices of $A$. unedo. Ants are here used as bioindicators of ecosystem health and surrogates for other animal groups.
\end{abstract}

\section{Handling Editor: Eric Rigolot}

Contribution of the co-authors Xavier Arnan: designing the experiment, supervising the field and laboratory work, and running the data analysis.

Olga Boet: supervising the laboratory work.

Anselm Rodrigo: designing the experiment, running the data analysis, and writing the paper.

L. Quevedo $(\bowtie) \cdot X$. Arnan $\cdot$ A. Rodrigo

CREAF, Campus UAB, 08193 Bellaterra, Catalunya, Spain

e-mail:1.quevedo@creaf.uab.es

X. Arnan

Faculty of Biology, TU Darmstadt, Schnittspahnstrasse 3, 64287 Darmstadt, Germany

O. Boet

Natural History Museum of Barcelona, Psg. Picasso s/n, 08003 Barcelona, Spain

\section{A. Rodrigo}

Facultat de Biociències, Universitat Autònoma Barcelona, 08193 Bellaterra, Catalunya, Spain
- Results Very limited effects of these post-fire management strategies on the structure and composition of ant communities were found. The lack of effects could be due to the reported small changes in physical conditions among treatments; or either, the most sensitive ant species to these post-fire management treatments might be the same ones affected by fire and, consequently, the ant species that would potentially be affected most were no longer in the study area.

- Conclusion The lack of any significant effects caused by these post-fire management practices on the associated fauna of $A$. unedo coppices points out the suitability of these treatments in these circumstances.

Keywords Ants $\cdot$ Biodiversity conservation .

Mediterranean · Post-fire management · Selective thinning .

Strawberry tree

\section{Introduction}

Logging and wildfires are two forest disturbances that promote major shifts in vegetation cover, which in turn lead to variations in microhabitat conditions and resource availability for associated fauna. Consequently, these changes may affect the composition and structure of animal communities. Accordingly, decreases in the diversity of forest fauna have been documented following different types of forest management activities (e.g., Thiollay 1997; Kavanagh and Webb 1998; Davis et al. 2001). In the case of wildfires, direct effects on forest fauna have also been reported, causing both mortality and fleeing, and indirect effects, such as the modification of forest habitats (e.g., Arnan et al. 2007; Rost et al. 2012). Thus, species that survive a fire or return after a fire may have difficulties living in the new conditions. On the other hand, there are species that are capable of reestablishing in these modified habitats that have different characteristics compared 
to before the fire (e.g., McCullogh et al. 1998; Rodrigo et al. 2008; Arnan et al. 2013b).

Wildfires, which are increasingly more frequent and intense (Piñol et al. 1998), are a major source of disturbance that has profound impacts on forests in the Mediterranean basin (Rodrigo et al. 2004). In many burned areas, different forestry management treatments are often applied after a fire, either to harvest burned wood (Rost et al. 2012; Quevedo et al. 2013) or to encourage faster regeneration. For example, selective removal of resprouts may be applied in areas dominated by species with a great capacity for post-fire resprouting (Quevedo et al. 2013). In this context, post-fire forest management practices can be understood as a second disturbance to the ecosystem, which could, in turn, affect the fauna that has established in the burned area and thus hinder their recovery (Apigian et al. 2006).

Ants are among the most diverse, abundant, and ecologically significant organisms on Earth (Hölldobler and Wilson 1990). They can modify the abiotic and biotic properties of their environment by performing a variety of ecological functions (e.g., Hölldobler and Wilson 1990; Zelikova et al. 2011). Consequently, ants are considered to be crucial components of most terrestrial ecosystems (Hölldobler and Wilson 1990; Lach et al. 2010). Ant communities are often used as a bioindicators of ecological change, arising from natural or anthropological disturbances (e.g., Vasconcelos et al. 2000; Andersen and Majer 2004; Hoffmann and Andersen 2003; Nakamura et al. 2007). In the case of fire, ant community recovery post-fire depends on both the direct mortality caused by the high temperature as well as by the changes in the vegetation cover caused by fire (Andersen et al. 2006; Arnan et al. 2006, 2007; Rodrigo and Retana 2006; Parr and Andersen 2008). Therefore, fires can generate changes in the composition of ant communities (Andersen et al. 2009; Arnan et al. 2006), including species richness and diversity, which in some cases increase (Mackay et al. 1991; Andersen et al. 2009), in others decrease (York 2000; Rodrigo and Retana 2006), or, as in some Mediterranean ecosystems, are not affected by fire (Arnan et al. 2006).

It is also known that forest management practices can affect ant communities (Vasconcelos et al. 2000; Dunn 2004; Gómez and Abril 2011), since in the short term it often implies a decrease in vegetation cover and may also alter food availability. However, as far as we know, there is no information available regarding whether post-fire salvage logging, which involves a modification of forest condition, affects the recovery of ant communities. This is of particular interest for species that inhabit closed canopy forests, as these species are the most affected by fire (York 2000; Parr and Andersen 2008; Andersen et al. 2006, 2009; Arnan et al. 2006; Rodrigo and Retana 2006). Therefore, it is important for the conservation of areas affected by fires, as is the case of the Mediterranean basin, to determine whether the post-fire forest management treatments often applied to large areas (Quevedo et al. 2013) can be considered a threat to the recovery of ant communities after a fire event.

The aim of this work is to determine whether forest management of a recently burned area dominated by a vigorous resprouting tree species affects the local fauna. In particular, this study focuses on the effects of the application of selective thinning of resprouts and the selective thinning of resprouts plus mechanical clearing of the surrounding vegetation on ant communities established after fire in a strawberry tree (Arbutus unedo L.) coppice. We test the following hypotheses: (a) post-fire forest management treatments on the strawberry tree coppices will change the structure and composition of ant communities, since environmental conditions will also change, and (b) the more intense the forest management treatment, the greater the changes to ant communities. This is the first study that analyzes the effects of selective thinning of resprout species on fauna in a post-fire scenario in a Mediterranean area, where wildfires have a great impact on biota.

\section{Materials and methods}

\subsection{Study area}

This study was undertaken in the north of the Baix Llobregat region $\left(41^{\circ} 35^{\prime} \mathrm{N}, 1^{\circ} 52^{\prime} \mathrm{E}\right.$, Catalonia, NE Iberian Peninsula), in a 240 -ha area affected by three canopy wildfires in recent years $(1985,1986$, and 1994). Before these fires occurred, this area was covered by Aleppo pine (Pinus halepensis Mill.) forests and, after the fire events, developed forested areas of strawberry trees (Arnan et al. 2013a). The study area is located between 390 and $500 \mathrm{~m}$ above sea level and in a region with a dry Mediterranean climate (according to Thornthwaite's humidity index), with a mean annual temperature of $13.5{ }^{\circ} \mathrm{C}$ and a mean annual precipitation of $650-700 \mathrm{~mm}$.

The strawberry tree (A. unedo L.) is a sclerophyllous tree species that belongs to the family of Ericaceae. In our study area, the strawberry tree forests had a density of $1,265 \pm 625$ individuals/ha and a number of $15,494 \pm$ 7,154 resprouts/ha, before treatments (Quevedo et al. 2013). In general, the strawberry tree has very vigorous resprouts after a disturbance (such as a cut or a fire) and can develop up to 60 resprouts/stump (Quevedo et al. 2013). This vigorous resprouting response involves a slow growth of stems due to the high competition for resources at the individual level. In these conditions, the lack of forest management promotes a high horizontal continuity and, as consequence, a high fire risk (Quevedo et al. 2013). 
2.2 Experimental design and application of post-fire experimental treatments

In 2006, we established four sampling zones in the study area (6.5 ha each one, hereafter, blocks), distance of 250-400 m between them, with a high density of $A$. unedo vigorously resprouted after the last fire (1994). In each block, we randomly chose three plots of $50 \mathrm{~m} \times 50 \mathrm{~m}$ of similar slope (10 to $30 \%$ ) and aspect (southwest) (distance between plots 40 $125 \mathrm{~m}$ ). All the selected plots showed similar forest structural characteristics. For a more detailed description of spatial position and characteristics of plots, see Quevedo et al. (2013).

In the winter of 2006-2007, the three plots within each block were assigned one of three management strategies at random: (1) control strategy (henceforth $\mathrm{C}$ ), in which nothing was done to the plot; (2) a selective thinning treatment (henceforth $\mathrm{T}$ ), in which resprouts were selectively removed with electric scissors (Electrocoup F3005) from all of the strawberry trees in the plot - one out of five resprouts was retained per individual (preserving the largest diameter resprouts); and (3) a selective thinning plus understory clearing treatment (henceforth $U$ ), in which the same selective thinning procedure was applied in tandem with the mechanical clearing of all the understory vegetation of the plot (for more details, see Quevedo et al. 2013).

\subsection{Field sampling}

\subsubsection{Characterization of the strawberry tree forest structure}

Vegetation structure is an important predictor of the structure and composition of ant communities (Retana and Cerdá 2000; Lassau and Hochuli 2004; Arnan et al. 2007). In order to characterize the type of habitat, we established a 40- $\mathrm{m} \times 40$ $\mathrm{m}$ physical grid in each plot, with each cell measuring $1 \times 1 \mathrm{~m}$. Each of the 1,600 cells was visually assigned one of the following three types of habitats: (1) Arbutus cover, when the majority of the cell was covered by strawberry tree; otherwise, (2) shrub cover, if plant coverage had a height between 1.20 and $3 \mathrm{~m}$; and (3) herbaceous cover, if that coverage was lower than $1.20 \mathrm{~m}$ or if no vegetation cover was present (bare and rocky soil). Then, we established the habitat composition of each plot as the percentage of each type of habitat.

To characterize the abiotic environment of each habitat type, we measured different environmental variables during each season of 2008 :

(a) Soil moisture. Three soil samples were taken from each plot, one for each of the three habitat types (total of 36 samples). Each sample, in turn, was formed by three subsamples of the same habitat, taken within the same plot. Soil samples were taken with a manual metal probe $\left(1,500 \mathrm{~cm}^{3}\right)$, placed in a sealed plastic bag, weighed in the laboratory, set to dry at $105{ }^{\circ} \mathrm{C}$ for $24 \mathrm{~h}$, and subsequently reweighed. The moisture content of the soil was obtained as the difference between the wet and dry weights.

(b) Percentage of shade provided by vegetation. This was determined by measuring the photosynthetically active radiation (PAR) with a Decagon Sunfleck SF 40 Ceptometer (Delta Devices, Cambridge, UK) at the time of maximum sunlight, above and below the vegetation canopy. Measures were obtained in each plot and habitat type directly (five repeats per habitat) (total of 36 samples). Then, the percentage of shade in each point was calculated as the percentage of the difference between the two PAR values (above and below) in respect to the above PAR value.

(c) Temperature. Temperature at ground level was obtained with continuous temperature registers (Stow Away Tidbit Temp Logger; Onset Computer Corp., Pocasset, MA) placed at ground level in each plot and habitat type. The sensors recorded temperature data every $30 \mathrm{~min}$ for a week. Since the sensors measured a maximum limit of $38^{\circ} \mathrm{C}$, the percentages of temperature data values below $20{ }^{\circ} \mathrm{C}$ and above $35{ }^{\circ} \mathrm{C}$ were used, representing the values out of the range of temperatures in which Mediterranean ants are active (Retana and Cerdá 2000).

\subsubsection{Ant sampling}

We used pitfall traps to measure the ground ant composition and abundance of each plot. Sampling was conducted in 2008, 2009, and 2010 and in May and July, when ant activity is highest in Mediterranean ecosystems (Cros et al. 1997). Pitfall traps were 7.5-cm-diameter $9.5-\mathrm{cm}$-deep plastic vials partially filled with water, soap, and salt. A $4 \times 4$ grid of traps with $5-\mathrm{m}$ spacing was established in each plot. The traps were placed in the center of the plot to minimize edge effects and were operated for 1 week for each sampling period. The contents of the 16 traps of each plot were lumped together to obtain a single sample per plot. The samples from the two sampling periods (May and July) from each plot and year were pooled for analysis, so that we had one sample for the whole activity period of ants (i.e., total number of ants per 16 traps across 14 days by each year). The ants were then sorted in the laboratory and identified to the species level according to Bernard (1968) and Espadaler (1990), supplemented with the identification of some specimens by Dr. Xavier Espadaler.

\subsection{Data analysis}

The effects of forest management $(\mathrm{C}, \mathrm{T}$, and $\mathrm{U})$ on habitat composition were analyzed using blocked univariate 
ANOVAs, where treatment was the main factor and block, the random factor. We conducted a separate analysis for each habitat type (Arbutus cover, shrub cover, and herbaceous cover). The effects of forest management and habitat type on the different abiotic variables (soil moisture, PAR, and temperature values below $20{ }^{\circ} \mathrm{C}$ and above $35^{\circ} \mathrm{C}$ ) were also analyzed using blocked univariate ANOVAs, where treatment, habitat, and season were the main factors and block, the random factor. We conducted a separate analysis for each abiotic variable and season (winter, spring, summer, and fall). We conducted post hoc comparisons using the Tukey test when the differences for the main factors were significant. The percentages of each habitat type and the PAR were arcsine-square root transformed in order to achieve data homoscedasticity. The statistical package SPSS (SPSS Inc. 2006) was used for these analyses.

To investigate the composition and structure of communities of ants in each plot, we computed the following indexes: (a) overall abundance of ants in pitfall traps; (b) species richness $(S)$; (c) Shannon diversity index $\left(H^{\prime}=-\sum_{p=1}^{S}\right.$ pi $\ln p$ $i$, where $p_{i}$ is the proportion of workers of the $i$ th species in traps, and $S$ is the number of species); and (d) the index of numerical dominance of the most abundant ant species (ID= $100\left(y_{1} / y\right)$, where $y_{1}$ is the abundance of the most abundant species and $y$ is the overall abundance of all ant species in the plot). Each ant species was assigned to a particular trophic guild according to its diet, as determined from Arnan et al. (2013b). We established the following guilds: liquid food (nectar and/or honeydew), liquid food and insects, only insects, insects and seeds, and only seeds. We analyzed the changes in the structure of the ant community and the proportion of individuals belonging to the different dietary guilds among treatments and years by using mixed linear models, where treatment, year, and their interaction were the main factors and block and plot the random factors. Overall abundance was log transformed, while the numerical dominance index and the relative abundance of each trophic guild were arcsine-square root transformed in order to achieve homoscedasticity. The statistical package $\mathrm{R}$ (version

Table $1 F$ values of the blocked univariate ANOVA tests for each season and for each variable that we used to characterize habitats (soil moisture $(\%)$, percentage of shade exerted by vegetation (PAR), percentage values

\begin{tabular}{|c|c|c|c|c|c|c|c|c|c|c|c|c|}
\hline \multirow[t]{2}{*}{ Source } & \multicolumn{3}{|c|}{ Winter } & \multicolumn{3}{|c|}{ Spring } & \multicolumn{3}{|c|}{ Summer } & \multicolumn{3}{|l|}{ Fall } \\
\hline & $\mathrm{T}$ & $\mathrm{H}$ & $\mathrm{B}$ & $\mathrm{T}$ & $\mathrm{H}$ & $\mathrm{B}$ & $\mathrm{T}$ & $\mathrm{H}$ & $\mathrm{B}$ & $\mathrm{T}$ & $\mathrm{H}$ & B \\
\hline Soil moisture (\%) & 2.4 & 0.8 & $4.1^{*}$ & $3.9^{*}$ & 1.2 & 2.1 & 0.1 & 0.6 & 1.1 & $5.6^{*}$ & 1.3 & $3.1^{*}$ \\
\hline Shade $(\%)$ & 1.9 & $55.5^{*}$ & $5.7 *$ & 0.1 & $86.5^{*}$ & $5.4^{*}$ & $4.3^{*}$ & $32.9 *$ & $12.3^{*}$ & 0.1 & $24.6^{*}$ & $9.9^{*}$ \\
\hline $\mathrm{T} 20$ & 0.6 & $3.4^{*}$ & $3.4^{*}$ & 0.7 & $4.7^{*}$ & $43.2 *$ & 1.2 & 2.0 & $5.9 *$ & 0.7 & 2.3 & $58.0^{*}$ \\
\hline $\mathrm{T} 35$ & $-^{\mathrm{a}}$ & $-^{\mathrm{a}}$ & $-^{\mathrm{a}}$ & 2.0 & 1.0 & 1.3 & 1.7 & 1.9 & $3.9^{*}$ & 0.7 & 2.4 & 2.7 \\
\hline
\end{tabular}

$* p \leq 0.05$; indicates significant values

${ }^{\mathrm{a}}$ Analysis not available due to lack of data

2.13.0; R Development Core Team 2008) was used in these analyses (function "lme" in package "nlme").

Significant differences in the ant community composition between treatments were determined with multivariate analysis using the program Primer 5.1.2 (Clarke and Gorley 2006). Ant abundance per plot was log transformed to obtain homoscedasticity. First, plots were ordered using nonmetric multidimensional scaling (NMDS), based on the Bray-Curtis similarity matrix. Then, analysis of similarities (ANOSIM) was used to test for significant differences in ant community composition related to forest management treatment $(C, T$, and $U)$. Ant species that occurred in less than three plots and that had a relative abundance of $<1 \%$ were excluded from the analysis. Finally, similarity percentages (SIMPER) were used to identify the ant species that contributed most to differences in community composition. All these analyses were conducted for each year $(2008,2009$, and 2010).

\section{Results}

\subsection{Habitat composition}

The U plots showed significant differences in habitat composition with respect to the $\mathrm{C}$ and $\mathrm{T}$ plots. These had a lower percentage of shrub cover $(F=30.5 ; p<0.0001 ; 6.2 \pm 1,19.2 \pm$ 2.0 , and $27.5 \pm 9.6 \%$ for the $\mathrm{U}, \mathrm{C}$, and $\mathrm{T}$ plots, respectively) and a greater percentage of herbaceous cover $(F=12.8$; $p=0.007 ; 64.5 \pm 8.9,39.6 \pm 10.0$, and $8.4 \pm 38.4 \%$ for the $\mathrm{U}$, $\mathrm{C}$, and $\mathrm{T}$ plots, respectively), with respect to the other two types of plots. There were no significant differences in the habitat composition between plots $\mathrm{C}$ and $\mathrm{T}(p>0.05)$. There were also no significant differences for the Arbutus cover category between plots of different treatments ( $p>0.05,41.2 \pm 11.1,34 \pm 5.8$, and $29.3 \pm 8.1 \%$ for the C, $\mathrm{T}$, and $\mathrm{U}$ plots, respectively). According to the different composition of habitats in the plots and to differences in the physical characteristics of habitats (Table 1), plots showed only small differences between treatments in soil moisture in

of temperature ground level below $20{ }^{\circ} \mathrm{C}$ (T20) and percentage above $\left.35{ }^{\circ} \mathrm{C}(\mathrm{T} 35)\right)$ in the treatment $(\mathrm{T})$, habitat $(\mathrm{H})$, and block (B) 
spring and fall and in shadow in summer, but no differences for temperature (Fig. 1).

\subsection{Ant community structure}

In total, 38,159 worker ants from 31 species were collected $(12,741,9,600$, and 15,818 from years 2008 ,
2009, and 2010, respectively) (Table 2). Species richness varied between 19 and 22 in the $\mathrm{C}$ plots, between 22 and 25 in the T plots, and between 20 and 22 in the $\mathrm{U}$ plots.

The mixed linear models showed no effects of treatments, years, or their interaction on species richness, the Shannon diversity index $\left(H^{\prime}\right)$, and the index of
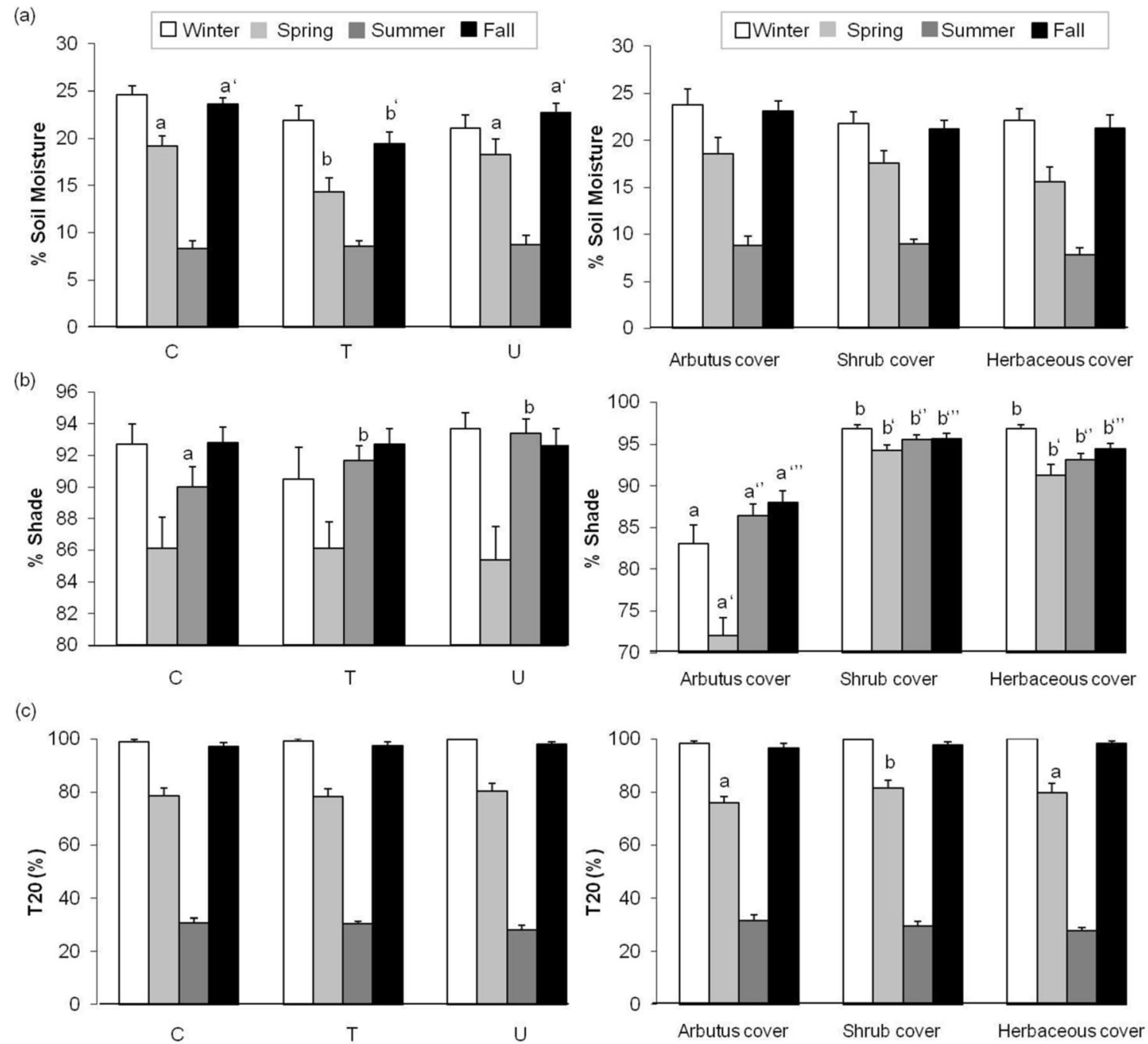

(d)
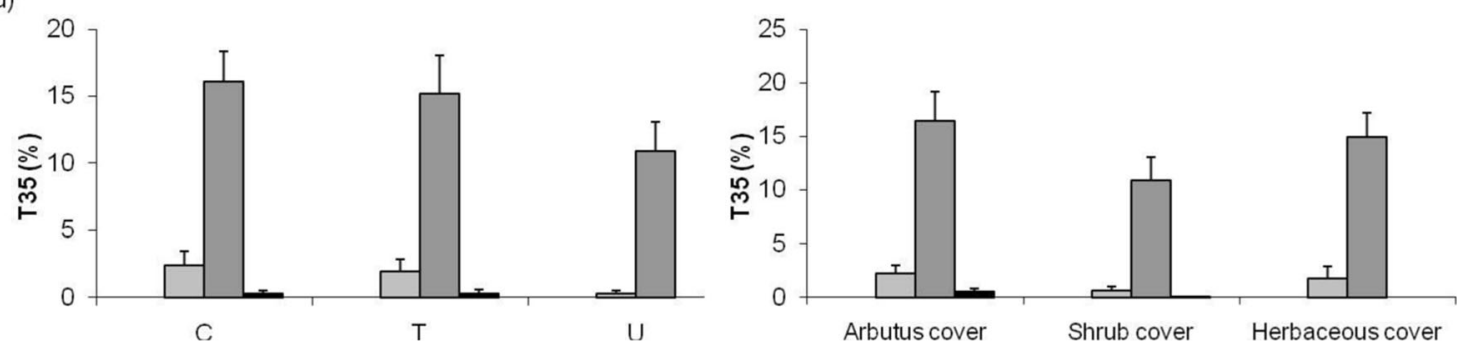

Fig. 1 Environmental variables measured for each forest management treatment and habitat for each season: winter (white bars), spring (light gray bars), summer (dark gray bars), and fall (black bars): a percentage of soil moisture, $\mathbf{b}$ percentage of shade, $\mathbf{c}$ percentage values of temperature below $20{ }^{\circ} \mathrm{C}(T 20)$, and $\mathbf{d}$ percentage values of temperature above

$35^{\circ} \mathrm{C}$ (T35). The vertical bars indicate standard error (SE) of the mean. Different letters indicate significant differences between categories, according to the Tukey post hoc tests. $C$ control, $T$ selective thinning, $U$ selective thinning plus understory clearing 
Table 2 List of ant species and number of worker ants collected in the plots of the three treatment intensities during the 3 years of study (2008, 2009, and 2010). The intensities of treatment are control (C), selective thinning (T), and selective thinning plus understory clearing (U)

\begin{tabular}{|c|c|c|c|c|c|c|c|c|c|c|}
\hline \multirow[t]{2}{*}{ Ant species } & \multirow[t]{2}{*}{ Diet } & \multicolumn{3}{|l|}{ C plots } & \multicolumn{3}{|l|}{ T plots } & \multicolumn{3}{|l|}{ U plots } \\
\hline & & 2008 & 2009 & 2010 & 2008 & 2009 & 2010 & 2008 & 2009 & 2010 \\
\hline \multicolumn{11}{|l|}{ Myrmicinae } \\
\hline Aphaenogaster gibbosa & $\mathrm{i}, \mathrm{s}$ & $23(2)$ & $13(1)$ & $25(2)$ & - & - & $5(1)$ & $4(3)$ & $4(2)$ & $4(2)$ \\
\hline Aphaenogaster subterranea & $\mathrm{i}$ & $6(2)$ & - & $3(1)$ & $3(2)$ & $3(2)$ & $4(1)$ & $10(1)$ & $4(1)$ & $12(1)$ \\
\hline Crematogaster scutellaris & 1 & - & - & - & $3(2)$ & $5(2)$ & $11(2)$ & $27(1)$ & $40(1)$ & $110(1)$ \\
\hline Crematogaster sordidula & 1 & $62(3)$ & $56(2)$ & $70(2)$ & - & - & - & $13(1)$ & $7(1)$ & $33(2)$ \\
\hline Goniomma blanci & $\mathrm{s}$ & $1(1)$ & - & - & - & - & - & - & - & - \\
\hline Leptothorax acervorum & $\mathrm{i}, 1$ & - & - & - & $2(1)$ & - & $1(1)$ & - & $4(1)$ & - \\
\hline Messor barbarus & $\mathrm{s}$ & - & - & $257(1)$ & $4(2)$ & $2(1)$ & - & - & - & - \\
\hline Messor bouvieri & $\mathrm{s}$ & $76(1)$ & - & - & $751(1)$ & $2(1)$ & $2,127(1)$ & - & - & - \\
\hline Messor capitatus & $\mathrm{s}$ & $487(2)$ & $849(2)$ & $1,317(2)$ & $29(2)$ & $365(2)$ & $127(2)$ & $130(2)$ & $421(3)$ & $704(2)$ \\
\hline Myrmecina graminicola & $\mathrm{i}, 1$ & - & $1(1)$ & - & - & - & - & $1(1)$ & - & - \\
\hline Myrmica spinosior & $\mathrm{i}$ & $2(1)$ & $1(1)$ & $1(1)$ & $19(3)$ & $11(2)$ & $20(2)$ & $26(1)$ & $9(2)$ & $16(1)$ \\
\hline Pheidole pallidula & $\mathrm{i}, \mathrm{s}$ & $844(4)$ & $425(4)$ & $728(4)$ & $504(4)$ & $227(4)$ & $723(4)$ & $193(4)$ & $183(4)$ & $502(4)$ \\
\hline Solenopsis sp. & i, s & $1(1)$ & - & $2(2)$ & $1(1)$ & - & $3(2)$ & $2(2)$ & $1(1)$ & $1(1)$ \\
\hline Temnothorax niger & $\mathrm{i}, 1$ & $57(4)$ & $25(3)$ & $36(4)$ & $19(3)$ & $12(3)$ & $34(3)$ & $17(4)$ & $13(4)$ & $19(4)$ \\
\hline Temnothorax racovitzai & $\mathrm{i}, 1$ & $23(4)$ & $6(4)$ & $29(4)$ & $9(3)$ & $6(4)$ & $19(4)$ & $27(3)$ & $25(4)$ & $30(4)$ \\
\hline Temnothorax recedens & $\mathrm{i}, 1$ & - & $1(1)$ & $1(1)$ & - & $1(1)$ & $7(2)$ & - & $1(1)$ & - \\
\hline Tetramorium semilaeve & $\mathrm{i}, \mathrm{s}$ & $2(1)$ & - & $2(1)$ & - & - & $1(1)$ & - & - & - \\
\hline \multicolumn{11}{|l|}{ Formicinae } \\
\hline Camponotus aethiops & $\mathrm{i}, 1$ & - & - & $1(1)$ & - & - & - & - & - & - \\
\hline Camponotus cruentatus & 1 & $1(1)$ & - & - & $405(1)$ & $94(1)$ & $98(1)$ & - & - & - \\
\hline Camponotus lateralis & $\mathrm{i}, 1$ & - & - & - & $1(1)$ & $5(2)$ & $9(2)$ & - & $1(1)$ & - \\
\hline Camponotus piceus & 1 & $50(4)$ & $56(4)$ & $39(4)$ & $89(4)$ & $51(4)$ & $36(4)$ & $23(3)$ & $24(3)$ & $47(3)$ \\
\hline Camponotus pilicornis & 1 & $55(4)$ & $71(4)$ & $73(4)$ & $45(4)$ & $55(4)$ & $55(4)$ & $28(4)$ & $58(4)$ & $84(4)$ \\
\hline Camponotus sylvaticus & 1 & $90(3)$ & $102(2)$ & $88(2)$ & $237(4)$ & $226(4)$ & $190(3)$ & $185(3)$ & $479(3)$ & $250(4)$ \\
\hline Formica gagates & $\mathrm{i}, 1$ & $133(2)$ & $72(2)$ & $235(2)$ & $572(3)$ & $323(2)$ & $189(2)$ & $1,228(1)$ & $1,229(2)$ & $755(2)$ \\
\hline Formica gerardi & $\mathrm{i}, 1$ & $6(2)$ & $11(3)$ & $6(2)$ & $80(4)$ & $20(2)$ & $47(3)$ & $2(2)$ & $1(1)$ & $1(1)$ \\
\hline Formica subrufa & $\mathrm{i}, 1$ & $459(1)$ & $465(2)$ & $441(2)$ & $432(3)$ & $480(3)$ & $507(3)$ & $1,088(2)$ & $2,050(2)$ & $3,547(2)$ \\
\hline Lasius cinereus & 1 & $1,192(3)$ & $15(1)$ & $17(3)$ & $1(1)$ & $14(1)$ & $4(2)$ & $1,076(2)$ & $69(3)$ & $476(2)$ \\
\hline Lasius myops & 1 & - & $4(1)$ & - & - & $1(1)$ & $2(2)$ & - & - & $3(1)$ \\
\hline Plagiolepis pygmaea & 1 & $467(4)$ & $191(4)$ & $380(4)$ & $511(4)$ & $201(4)$ & $346(4)$ & $343(4)$ & $289(4)$ & $556(4)$ \\
\hline Polyergus rufescens & $\mathrm{i}, \mathrm{s}$ & - & - & - & $1(1)$ & - & - & - & - & $1(1)$ \\
\hline \multicolumn{11}{|l|}{ Dolichoderinae } \\
\hline Tapinoma nigerrimum & $\mathrm{i}, 1$ & $223(4)$ & $65(4)$ & $101(4)$ & $158(4)$ & $73(4)$ & $118(3)$ & $182(3)$ & $82(3)$ & $132(3)$ \\
\hline Total number of individuals captured & & 4,260 & 2,429 & 3,852 & 3,876 & 2,177 & 4,683 & 4,605 & 4,994 & 7,283 \\
\hline Species richness & & 22 & 19 & 22 & 23 & 22 & 25 & 20 & 22 & 21 \\
\hline
\end{tabular}

Parentheses indicate the number of plots in which each species appears for each year and intensity of treatment. Diet data are based on Arnan et al. (2013b)

$i$ insects, $s$ seeds; $l$ liquid food (nectar and/or honeydew)

numerical dominance of the most abundant ant species (Table 3). Significant differences were found between the years 2008 and 2009, as well as between 2009 and 2010 , in terms of total ant abundance $(467 \pm 61,356 \pm$ 88 , and $705 \pm 158$ ants per plot for the years 2008, 2009, and 2010, respectively) (Table 3).

\subsection{Ant community composition}

The ANOSIM analyses showed only a slight effect of treatments on ant community composition in the long term (year 2010; global $R=-0.238, p=0.014$, Fig. $2 ; p>0.05$ for the years 2008 and 2009). The only significant differences were 
Table 3 Effect of treatment (forest management C, T, and U) and year (2008, 2009, and 2010) on variables describing structure of ant communities. $F$ values, significance $(p)$, and degrees of freedom (df) come from the ANOVA tables of the mixed linear models

\begin{tabular}{|c|c|c|c|c|c|c|c|c|c|}
\hline \multirow[t]{2}{*}{ Source of variation } & \multirow[t]{2}{*}{$\mathrm{df}$} & \multicolumn{2}{|c|}{ Total ant abundance } & \multicolumn{2}{|c|}{ Richness } & \multicolumn{2}{|c|}{ Shannon diversity index $\left(H^{\prime}\right)$} & \multicolumn{2}{|c|}{ Numerical dominance } \\
\hline & & $F$ & $p$ & $F$ & $p$ & $F$ & $p$ & $F$ & $p$ \\
\hline Treatment & 2 & 1.2 & 0.374 & 1.7 & 0.256 & 1.8 & 0.247 & 2.3 & 0.185 \\
\hline Year & 2 & 9.3 & $0.002 *$ & 1.6 & 0.236 & 0.3 & 0.777 & 0.2 & 0.828 \\
\hline Treatment $\times$ year & 4 & 0.4 & 0.819 & 1.4 & 0.278 & 0.1 & 0.981 & 0.1 & 0.961 \\
\hline
\end{tabular}

${ }^{*} p<0.05$; indicates significant value

between the $\mathrm{C}$ and $\mathrm{U}$ plots (post hoc analyses: $p=0.029$ between the $\mathrm{C}$ and $\mathrm{U}$ plots, $p=0.114$ between the $\mathrm{C}$ and $\mathrm{T}$ plots, and $p=0.057$ between the $\mathrm{T}$ and $\mathrm{U}$ plots). Nevertheless, Fig. 2 shows no clear separation of treatments. In fact, the negative value of the global $\mathrm{R}$ statistic indicates a very large variability within plots of the same treatment, but very low variability between treatments. So, despite the fact that it seems that there were significant differences between ant community from $\mathrm{C}$ and $\mathrm{U}$ plots, they were very slight and difficult to assess given the high variability within treatments. The SIMPER analysis revealed that the species that contributed to the slight dissimilarity between $\mathrm{C}$ and U plots were Messor capitatus (12.07\%), Formica subrufa (10.52\%), Formica gagates (10.17\%), and Pheidole pallidula $(8.78 \%)$.

\subsection{Ant dietary guilds}

The relative abundance of each ant dietary guild was not significantly different between treatments or years. Their interaction was not significant either (mixed linear models, $p>0.05$ in all cases).

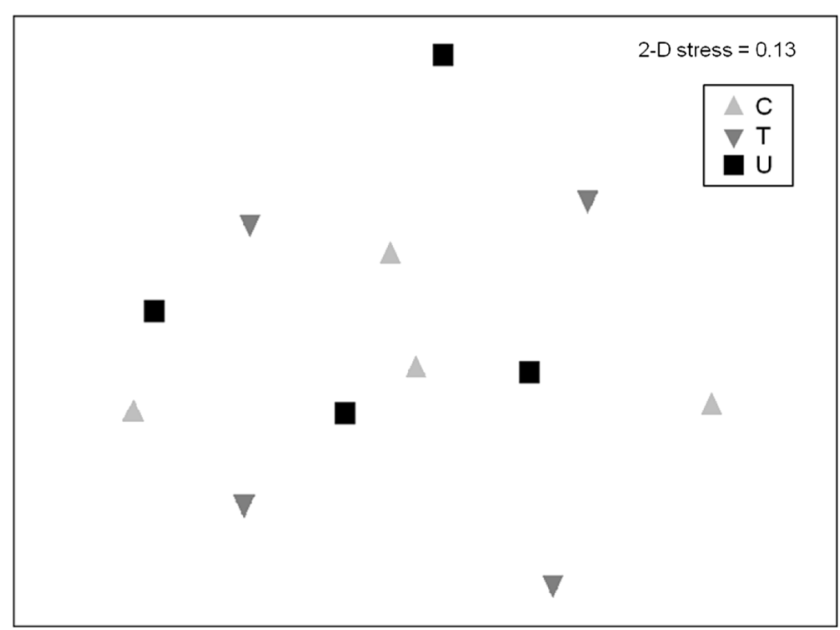

Fig. 2 Nonmetric multidimensional scaling (NMDS) ordination in two dimensions of plots based on ant abundance data in 2010. $C$ control, $T$ selective thinning, $U$ selective thinning with understory clearing

\section{Discussion}

This work has demonstrated that there is virtually no effect of post-fire selective thinning on the structure of ant communities inhabiting the $A$. unedo coppices of our study area. The applied forest management treatments did not cause any impact, either positive or negative, on the total abundance, species richness, diversity, dominance, or the composition of ant community, neither in the short or the medium term (Table 3, Fig. 2). This result contradicts numerous works, much from the tropics of Amazon, where it has been found that the application of selective thinning leads to a negative impact on the species richness or the composition of ant species (e.g., Roth et al. 1994; Vasconcelos et al. 2000; Dunn 2004; Nakamura et al. 2007; Palladini et al. 2007), and other research on faunal groups also used as bioindicators, as for example, beetles (Davis et al. 2001), birds (Thiollay 1997), small mammals, reptiles, and amphibians (Kavanagh and Webb 1998). However, there are other studies that show similar results to those provided in this work that indicate that some forest harvesting does not negatively affect the overall animal biodiversity (Azevedo-Ramos et al. 2006) and have a minimal impact on ant communities (Vasconcelos et al. 2000; Andersen et al. 2009). Several of these works agree that one of the key factors that determine if forest harvesting will have an impact on the richness and/or composition of biodiversity is the intensity, and also the frequency, of treatments (Dunn 2004; Andersen et al. 2009; Gómez and Abril 2011). The more intense the treatment, the more change is generated on the vegetation cover, causing a larger impact on the whole ecosystem (Maeto and Sato 2004; Palladini et al. 2007). Nonetheless, we were unable to detect this larger effect in even our most intense treatment, which involved both the selective thinning and the clearing of understory vegetation.

Soil moisture determines ant foraging activity, the abundance of food resources, the suitability of places to make their nests, as well as predation by other species of ants (Wang et al. 2001). Also, ground temperature has a direct effect on nest temperature levels and an indirect effect on food supply via vegetation growth (York 2000). In fact, when we applied selective thinning along with the clearing of the understory, 
we were able to modify proportions of habitats, resulting in a greater availability of more open habitats. However, there are only small differences in ground temperature between habitats but similar soil moisture, probably due to an early resprouting of the understory vegetation. As a consequence, although this change in open habitat proportion, differences between treatments as a whole in physical conditions were very small (Fig. 1). So, these small changes were not great enough to affect the structure or the composition of the ant community.

Our results also show that these treatments could not modify the relative abundance of ant dietary guilds in the study area. Although it might make more sense that clearing undergrowth would cause a decrease in food resources, such as seeds generated by the shrub layer and insects that inhabit this environment (termites, springtails, other ants, etc.) (Hölldobler and Wilson 1990; Arnan et al. 2006), this did not yet have any effect or was not important enough to negatively impact ants that feed on these food resources. On the other hand, the shrubs present in our study area have a high resprouting capacity after cutting (Pistacia lentiscus, Quercus coccifera, Thymus vulgaris, Viburnum tinus, etc.), so that they recover quickly and with ease.

One possible explanation for the lack of any effect of postfire forest management treatments on ant community might be that the ant species most sensitive to these forest practices are the same ones that are also most affected by changes in vegetation promoted by fire, i.e., tree-dwelling ant species (Arnan et al. 2013b). Consequently, the ant species that would be most affected by post-fire management treatments were no longer in the study area. As such, post-fire forest management might affect the process of post-fire colonization in the long term although we did not detect any evidence in the short and midterm.

At any rate, the act of reducing forest cover by selective thinning has minimal effect on the ant community of this area, nor does it if the understory is also removed. This implies that the application of such treatments that have clear advantages in the recovery of the structure of these burned forests and in the decrease of fire risk (Quevedo et al. 2013) may be advisable on a regional basis without any negative effect in the ant fauna. In fact, as these treatments favor the height and diameter growth of the stands of the strawberry tree (Quevedo et al. 2013), accelerating the recovery of these forests towards more structured and closed might even encourage, in the medium and long term, the appearance of ant species normally only found in more closed areas (Arnan et al. 2006; Rodrigo and Retana 2006). However, despite the fact that ants can be used as bioindicators of the response of fauna in general (Hoffmann and Andersen 2003; Andersen and Majer 2004), it would be appropriate to check the effect of these treatments on other faunal groups. In this context, analyzing the effect of similar treatments on the faunal community in the medium or long term is important in order to be able to understand the overall effect of these post-fire forest management treatments in the biodiversity of burned areas.

Acknowledgments We are very grateful to Alba Lázaro and Mariona Ferrandiz for field and laboratory assistance.

Funding This study has been funded by the Spanish "Ministerio de Ciencia e Innovación” project Consolider-Ingenio Montes, CSD200800040 to AR.

\section{References}

Andersen AN, Majer JD (2004) Ants show the way Down Under: invertebrates as bioindicators in land management. Front Ecol Environ 2:291-298

Andersen AN, Hertog T, Woinarski JCZ (2006) Long-term fire exclusion and ant community structure in an Australian tropical savanna: congruence with vegetation succession. J Biogeogr 33:823-832

Andersen AN, Penman TD, Debas N, Houadria M (2009) Ant community responses to experimental fire and logging in a eucalypt forest of south-eastern Australia. For Ecol Manag 258:188-197

Apigian KO, Dahlsten DL, Stephens SL (2006) Fire and fire surrogate treatment effects on leaf litter arthropods in a western Sierra Nevada mixed-conifer forest. For Ecol Manag 221:110-122

Arnan X, Rodrigo A, Retana J (2006) Post-fire recovery of Mediterranean ground ant communities follows vegetation and dryness gradients. $\mathrm{J}$ Biogeogr 33:1246-1258

Arnan X, Rodrigo A, Retana J (2007) Uncoupling the effects of shade and food resources of vegetation on Mediterranean ants: an experimental approach at the community level. Ecography 30:161-172

Arnan X, Quevedo L, Rodrigo A (2013a) Forest fire occurrence increases the distribution of a scarce forest type in the Mediterranean Basin. Acta Oecol 46:39-47

Arnan X, Cerdà X, Rodrigo A, Retana J (2013b) Response of ant functional composition to fire. Ecography 36:1-11

Azevedo-Ramos C, de Carvalho O Jr, Do Amaral BD (2006) Short-term effects of reduced-impact logging on eastern Amazon fauna. For Ecol Manag 232:26-35

Bernard F (1968) Les fourmis (Hymenoptera Formicidae) d'Europe Occidentale et Septentrionale. Collection Faune de l'Europe et du Bassin Mediterraneen, Masson, Paris

Clarke KR, Gorley RN (2006) PRIMER v6: user manual tutorial, Primere. Plymouth Marine Laboratory, Plymouth, UK

Cros S, Cerdà X, Retana J (1997) Spatial and temporal variations in the activity patterns of Mediterranean ant communities. Ecoscience 4: 269-278

Davis AJ, Holloway JD, Huijbregts H, Krikken J, Kirk-Spriggs AH, Sutton SL (2001) Dung beetles as indicators of change in the forests of northern Borneo. J Appl Ecol 38:593-616

Dunn RR (2004) Managing the tropical landscape: a comparison of the effects of logging and forest conversion to agriculture on ants, birds and Lepidoptera. For Ecol Manag 191:215-224

Espadaler X (1990) Claus per identificar les formigues (obreres) (Hymenoptera, Formicidae) del Vallès (Catalunya). El medi natural del Vallès. II Col-loqui de Naturalistes Vallesans. ADENC-CEEM, Sabadell, Spain, pp 117-127

Gómez C, Abril S (2011) Selective logging in public pine forests of the central Iberian Peninsula: effects of the recovery process on ant assemblages. For Ecol Manag 262:1061-1066

Hoffmann BD, Andersen AN (2003) Responses of ants to disturbance in Australia, with particular reference to functional groups. Aust Ecol 28:444-464 
Hölldobler B, Wilson EO (1990) The ants. The Belknap Press of Harvard University Press, Cambridge, MA

Kavanagh RP, Webb GA (1998) Effects of variable-intensity logging on mammals, reptiles and amphibians at Waratah Creek, southeastern New South Wales. Pac Conserv Biol 4:326-347

Lach L, Parr CL, Abbott KL (2010) Ant ecology. Oxford University Press, Oxford, UK

Lassau SA, Hochuli DF (2004) Effects of habitat complexity on ant assemblages. Ecography 27:157-164

Mackay WP, Rebeles A, Arredondo HC, Rodríguez AD, González DA, Vinson SB (1991) Impact of slashing and burning of a tropical rain forest on the native ant fauna (Hymenoptera: Formicidae). Sociobiology 18:257-268

Maeto K, Sato S (2004) Impacts of forestry on ant species richness and composition in warm-temperature forests of Japan. For Ecol Manag 187:213-223

McCullogh DG, Werner RA, Neumann D (1998) Fire and insects in northern and boreal forest ecosystems of North America. Annu Rev Entomol 43:107-127

Nakamura A, Catterall CP, House APN, Kitching RL, Burwell CJ (2007) The use of ants and other soil and litter arthropods as bio-indicators of the impacts of rainforest clearing and subsequent land use. $\mathrm{J}$ Insect Conserv 11:177-186

Palladini JD, Jones MG, Sanders NJ, Jules ES (2007) The recovery of ant communities in regenerating temperate conifer forests. For Ecol Manag 242:619-624

Parr CL, Andersen AN (2008) Fire resilience of ant assemblages in longunburnt savanna of northern Australia. Aust Ecol 33:830-838

Piñol J, Terradas J, Lloret F (1998) Climate warming, wildfire hazard, and wildfire occurrence in coastal eastern Spain. Clim Change 38:345357

Quevedo L, Arnan X, Rodrigo A (2013) Selective thinning of Arbutus unedo coppices following fire: effects on growth at the individual and plot level. For Ecol Manag 292:56-63

R Development Core Team (2008). R: a language and environment for statistical computing. R Foundation for Statistical Computing,
Vienna, Austria. ISBN 3-900051-07-0, URL http://www.R-project. org

Retana J, Cerdá X (2000) Patterns of diversity and composition of Mediterranean ground ant communities tracking spatial and temporal variability in the thermal environment. Oecologia 123:436-444

Rodrigo A, Retana J (2006) Post-fire recovery of ant communities in Submediterranean Pinus nigra forests. Ecography 29:1-9

Rodrigo A, Retana J, Pico FX (2004) Direct regeneration is not the only response of Mediterranean forests to large fires. Ecology 85: 716-729

Rodrigo A, Sardà-Palomera F, Retana J, Bosch J (2008) Changes of dominant ground beetles in black pine forests with fire severity and successional age. Ecoscience 15:442-452

Rost J, Clavero M, Brotons L, Pons P (2012) The effect of postfire salvage logging on bird communities in Mediterranean pine forests: the benefits for declining species. J Appl Ecol 49:644-651

Roth DS, Perfecto I, Rathcke B (1994) The effects of management systems on ground-foraging ant diversity in Costa Rica. Ecol Appl $4: 423-436$

SPSS, Inc (2006) SPSS Base 15.0.1 for Window's users guide. SPSS Inc, Chicago

Thiollay JM (1997) Disturbance, selective logging and bird diversity: a Neotropical forest study. Biodivers Conserv 6:1155-1173

Vasconcelos HL, Vilhena JMS, Caliri GJA (2000) Responses of ants to selective logging of a central Amazonian forest. J Appl Ecol 37: 508-514

Wang C, Strazanac JS, Butler L (2001) Association between ants (Hymenoptera: Formicidae) and habitat characteristics in oakdominated mixed forests. Environ Entomol 30:842-848

York A (2000) Long-term effects of frequent low-intensity burning on ant communities in coastal blackbutt forests of southeastern Australia. Aust Ecol 25:83-98

Zelikova TJ, Sanders NJ, Dunn RR (2011) The mixed effects of experimental ant removal on seedling distribution, belowground invertebrates, and soil nutrients. Ecosphere 2: art63 